чающую в себя книги, научные инструменты, маркеры, обозначающие сословный статус ученых и патронов-основателей научных институций. Гравюры, где несколько ученых объединены одной рамкой и общим названием, позволяют обозначить их достижения относительно друг друга. В групповых изображениях ученых доминирует принцип социальной иерархии, тем не менее, перед нами репрезентация идеального представления о сообществе ученых. Это особенно отчетливо видно, когда на картине или гравюре присутствует патрон-основатель институции.

На картинах и гравюрах отражены также принципы организации научных корпораций. В парадных изображениях гильдии хирургов Антверпена XVII в. и на гравюре в издании Томаса Спрата «Истории Лондонского королевского общества» продемонстрирована идея самоуправления при наличии иерархии внутри сообщества, тогда как картина А. Тестелена, изображающая представление Лю- довику XIV Королевской академии наук, отражает прямое вмешательство премьер-минстра Ж-Б. Кольбера и короля в управление научным сообществом.

\section{Список литературы}

1. Бэкон Ф. Сочинения в двух томах. Т.2. - М.: Наука, 1972.

2. Histoire de l'Academie Royale des Sciences. T. II. - 1699. P. 349-360. [Электронный ресурс]. - Режим доступа: http://www.europeana

3. Huygen C. Horologium oscillatorium sive de motu pendulorum ad horologia aptato demonstrationes geometricae. - Paris: F. Muguet, 1673.

4. Verduin C.J. A portrait of Christiaan Huygens. In Fletcher, K. (ed) Proceedings of the International Conference 'Titan - from Discovery to Encounter', Noordwijk, the Netherlands (ESA SP1278), ESA Publications Division, Noordwijk, 2004 [Электронный ресурс]. - Режим доступа: http://www.leidenuniv.nl/ fsw/verduin/stathist/huygens/acad1666/index.html

\title{
Г.Г. ХУБУЛАВА
}

\section{ЛИЦО И ЛИЧНОСТЬ: ОНТОЛОГИЧЕСКИЙ АСПЕКТ}

Статья посвящена феномену взаимосвязи внешности и личности. Наше лицо и личность находятся в отношениях вечной двойственности и единства в системе «Я - Другой». Они не тождественны, но и не разделимы. В истории мысли амбивалентность взаимоотношений лица и личности прошла путь от природной индивидуально-личностной средневековой парадигмы через рационалистическое тождество внешности и личности к экзистенциальной относительности.

Ключевые слова: лицо, личность, лик, ипостась, сознание, маска, Другой.

4 асто бывает так, что очень серьезная «взрослая» беседа начинается с наивного «детского» вопроса, ответ на который на первый взгляд представляется нам очевидным. Вот и я хочу начать беседу о природе лица и личности с простого «детского» вопроса: Что такое лицо? Это - кожа, мышцы, кости и связки? Это - карта наших с вами чувств и эмоций? Это наша горячо любимая нами персона? Это - образ Божий, данный нам?

Ответов может быть множество, и все они как ни странно по-своему верны. И все же, кого мы наблюдаем утром в зеркале? Самый распространенный ответ: себя, конечно себя. Однако что мы говорим себе, когда человек в зеркале удивляет или расстраивает нас своим видом? В таком случае мы часто восклицаем: «Да неужели это я?» Удивительно, но мы вновь оказываемся правы.

Лицо телесное - это всегда маска, всегда Другой.
Слово «персона» произошло от греческого $\pi \rho \sigma^{\circ} \sigma \pi$ о («prosopon») - «через отверстие» (в античном театре голос актера звучал через отверстие в маске). И коль уж стало так модно именовать многих из нас «очень важными персонами», то придется признать, что лицо - всего лишь маска.

«Другой» - это не «Я», тот, кто противостоит мне, находится по ту сторону меня, моих ценностей, моего мировоззрения. «Другой» - такой же, как «Я»: он мыслит, чувствует, говорит. Мое отражение в зеркале (лицо) является Другим по отношению ко мне как личности, выражая при этом ее внешнюю форму и структуру.

Фактически лицо (как внешность) - это персонаж. Когда я говорю, что лицо - это Другой (L'autre), я имею в виду простую ситуацию: вообразите мир без отражающих поверхностей. Лицо теряет смысл и функцию, когда его никто не видит, включая носителя. Да, лицо - сво- 
его рода ландшафт личности, оно ассоциируется у нас с человеком его «носящим», но человек ассоциируется не только с лицом. Лицо - Другой, оно образ и подобие.

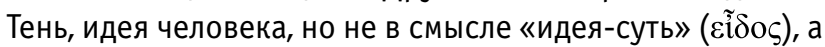
лишь в смысле «автограф, визитка».

Лицо есть Другой, к которому мы начинаем проявлять живой интерес, только начав общаться со своим отражением, то есть примерно на третьем месяце жизни.

Психоаналитик и философ, ученик Фрейда Жак Лакан в работе «Стадия_зеркала» утверждает, что наше отражение и узнавание себя в нем в младенчестве формирует «ту символическую матрицу, в которой “Я" оседает в первоначальной форме, прежде чем объективироваться»" $[1$, p. 2]. То есть человек уже осознает, что видит в зеркале кого-то, но еще не может судить о нем в терминах «я»- «Не Я».

«Зеркальный образ является, кажется, порогом видимого мира, если мы замечаем роль зеркального аппарата в появлении дубля, в котором о себе заявляют, впрочем, гетерогенные реалии» [1, p. 4]. Видимый мир замыкается для нас на образе в зеркале, которое отражает как наши физические, как и психические свойства.

Итак: «...стадия зеркала есть драма, которая измышляет фантазмы, постепенно переходящие к водруженным на себя доспехам некой отчуждающей идентичности» [1, p. 6]. Драма эта как раз и состоит в нашей неразрывной связи с тем обликом, нашим лицом, которое мы, тем не менее, понимаем как «дубль», «фантазм», «Другой».

Под «отчуждающей идентичностью» можно понимать тот самый возглас узнавшего себя в зеркале: «Да неужели это я?».

Иосиф Бродский придал этой проблеме лаконичную поэтическую форму:

\author{
Сумев отгородиться от людей, \\ я от себя хочу отгородиться. \\ Не изгородь из тесаных жердей, \\ а зеркало тут больше пригодится [2, с. 9].
}

Как выйти из этого странного противоречия? Даже беглый взгляд побуждает нас задать еще один вопрос: а что вообще значит видеть?

Согласно платоновскому «Тимею», зрительное восприятие возможно благодаря одновременному истечению световых лучей из видящего глаза и из видимого им предмета, причем оба луча сливаются («слияние лучей», synaygeia) в нечто одно, целое и неделимое, «зрительное тело». Эта теория относится не только к зрению, но и ко всему восприятию в целом. Synaygeia (синавгия) предстает «зрительным телом», лишенным каких бы то ни было фактических свойств видимого и видящего: оно есть чистый смысл или, как говорит Платон, эйдос - чистая идея. Это непосредственная данность, в которой сущность и явление слиты в одно неразличимое целое.

Мы видим свет, потому что он различает и видит нас,

\footnotetext{
${ }^{1}$ B оригинале: «la matrice symbolique où le je se précipite en une forme
} primordiale, avant qu'il ne s'objective». потому что мы видимы им и видим себя изнутри этой видимости. Вся новизна света в этом абсолютном ощущении иного, которое уже пронизывает нас; в этом встречном взгляде, который вплетается в мой и фиксирует его, замирая в нем как свет.

Узнавая свое отражение в зеркале, мы как будто захватываем чужую позицию, смотрим со стороны то ли со стороны зеркала, то ли извне его, но в любом случае высвобождая взгляд из-под власти собственного лица, подчиняя свою мимику этому свободно парящему взгляду.

При всей культурной значимости лица уже на уровне повседневного опыта поражает некая его призрачность, а долгое всматривание и вовсе превращает лицо в маску, заставляя вспомнить сартровские слова о лице как о дыре бытия (Le visage n'est qu'un trou dans l'existance). Умозрительно лицо - пустое пятно, открытое место, и, возможно, как раз поэтому все, что каким-либо образом занимает в нашем сознании место, обладает для нас особой силой воздействия, силой реального как такового. Собственное лицо не противится зрению и известно нам во множестве искусственных и естественных отображений, но и не принадлежит им. Лицо никогда так и не становится в полной мере объектом, почему мы и говорим о нем скорее как о некоем пустом объекте, пустом или, по крайней мере, никогда полностью не заполненном месте.

Мы лишены возможности напрямую видеть свое лицо как внешнее, по крайней мере, как завершенное в какихто внешних (зримых) формах. За редким исключением нам не снится собственное лицо, оно отсутствует как образ. Отсутствие собственного лица восполняется своеобразным предъявлением чужих лиц.

Взгляд в зеркало всегда сугубо вторичен: только потому я и узнаю себя в отражении, что уже и так знаю, что это я. Отражение не то, что позволяет нам видеть свое «Я»: глаза не видят нашей «сущности» как «сущего», для этого нужны глаза Другого. Лицо служит экраном для нашего контакта с Другим. Взгляд Другого свидетельствует о нас, позволяя нашему лицу, увиденному кем-то, стать для нас «реальным». Поэтому, даже когда во сне мы видим чужое лицо глядящего на нас человека, в действительности мы пытаемся посмотреть на себя. То же происходит, когда мы вспоминаем чье-то лицо. Видеть - значит показывать себя Другому. Выставлять себя напоказ (Voir veut dire se montrer aux autres, s'etaler) - делится с нами своим соображением Лакан [1, p. 20].

Прежде, чем мы научимся вызывать в самих себе образы прошлого, мы уже находим их явленными в лице Другого.

В лице Другого субъект встречается с собственным ожиданием того, что должно возникнуть и состояться как его собственное лицо. Узнавание себя в зеркале возможно лишь потому, что весь предшествующий этап и был ничем иным, как овладением своим лицом в лице Другого. 
Можно сказать, что лицо Другого являет собой некое другое настоящее, в котором все еще продолжает сбываться прошедшее и уже каким-то образом совершается будущее. Лицо Другого наделяет осмысленностью восприятие, предоставляя нам себя как отправную форму видения.

Показывая себя Другому, мы выходим за грань разумного, за границу власти органов чувств. «Душа» у Платона и Аристотеля не «психологическая» реальность, она рассматривается как умозрительная категория. Наша «душа»

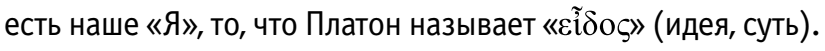

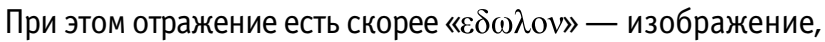
призрак, двойник и обозначает копию или образ идеи, не отражающий ее сущности. Душа видит себя в душе другого, когда разговаривает с ним, это «субъект» речи.

Дело в том, что лицо не является синонимом нашего «Я», оставаясь при этом его зримым и осязаемым воплощением.

Гегель, приводя в пример работу художника над портретом, так говорит об этой двойственности в своей «Эстетике»: «0дно дело передать лицо в тех поверхностных и внешних чертах, которые лицо спокойно сидящего перед портретистом человека являет ему именно в данный момент, и совершенно другое дело уметь изобразить те истинные черты, которые представляют собою выражение самой настоящей души данного человека. Ибо для идеала требуется, чтобы внешняя форма сама по себе соответствовала душе. То есть той ненаглядной, абсолютной сути, лику, в котором лицо отражает дух сущностный, личностный» [3, с. 168].

Вспомним также главную метафору романа Оскара Уайльда «Потрет Дориана Грея», где лицо и портрет (облик) молодого и красивого господина меняются местами, и все тяготы физического старения отражаются только на холсте, однако «дух сущностный личностный» неотвратимо меняется, в соответствии с возрастом, вопреки желанию своего вечно молодого (внешне) обладателя.

Итак, лицо, являясь отражением нашей личности, нашего «я», не становится при этом его синонимом. Поэтому воспринимается нами (как личностью) одновременно и как «я», и как «кто-то Другой».

Но, говоря о лице и личности в духе дуалистического единства-противоречия, нам никак не удастся уклониться от другого, не менее важного вопроса.

Пусть наше лицо есть «образ», «облик», «чистая структура» и телесная маска нашего «Я». Маска, неотделимая от этого «Я», и все же «Другая». Но что тогда такое «лицо живущее», лицо-личность и чистый дух, о котором говорится в противоположность лицу телесному?

И теперь уже не обойтись без религиозных аллюзий. Поскольку «лицо-личность» (ипостась) - это (в связи с христианской трактовкой понятия «личность») первоначально Божественное Лицо, которое лишь впоследствии переносится на человека.

Лицо становится ликом как раз в тот момент, когда утрачивает свою субъективность, свои привычные черты.
Вспомните Преображение. В Иисусе Христе Всесильный и невидимый Бог Ревнитель обретает плоть и лицо, но Христос явно намекает ученикам, что, видя Его лицо, они не видят Его сущности: «Когда вознесете - (на крест) Сына человеческого, тогда узнаете, что это Я (Есмь)» (Ин. 8:24; 8:28). А вот что говорится о Преображении: «...преобразился пред ними: и просияло лице Его, как солнце, одежды же Его сделались белыми, как свет и пали все трое в страхе великом» (Мф.17:2-3). Лицо исчезает, возникает Лик.

В учении о Святой Троице ключевую роль играет выработанный в IV веке отцами-каппадокийцами

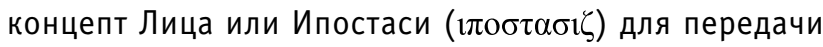
специфического рода отдельного бытия Отца, Сына и Святого Духа. Основным качеством данного бытия виделась конкретная выраженность, индивидуальная отличность в соответствии с понятием индивидуальности, индивида, особи - как носителя определенной роли. Однако бытие Божественное, совершенное и абсолютное, в отличие от земного обладает еще одним качеством: всякое содержание данного бытия носит характер совершенной выраженности, явленности, открытости. Именно оно может быть определено как тождественное личности лицоипостась [4].

Итак, поскольку в Человеке нам явлен Образ Божий, а Бог воплотился в человеке, то личность, скрывающая себя за лицом, есть Ипостась, Лик, являющийся нам, когда исчезает лицо. Лицо же являет образ и скрывает суть «носящей» его личности.

Под «ипостасью», «лицом» и латинским «индивидуум» Святые отцы понимали одно и то же. А именно: нечто состоящее из субстанции и акциденций (сути и качеств), существующее само по себе и самостоятельно, поддающееся исчислению и выражающее такого-то, например,

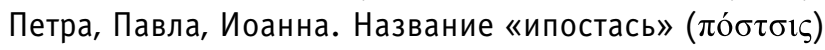

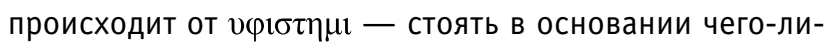
бо, быть в основании, служить основой для чего-либо. У Аристотеля это понятие означало истинно существующее в противоположность концептам и идеям и часто употреблялось как синоним слова «природа». Кроме того, он понимался как эквивалент латинского sub-stantia. B нем более определенно, чем в термине «природа» проявлялось индивидуальное существование. Потому в терминологии Аристотеля, воспринятой византийской мыслью, ипостась - это «вторая природа», то есть конкретное существование конкретного предмета. (По Аристотелю «нет природы без ипостаси».)

При этом «индивидуум» - это просто «неделимое», «нераздельное». Просто «самый настоящий объект, и больше ничего». И стол и любая кошка есть такой «индивидуум», - напоминает А.Ф. Лосев [5, с. 6]. А ипостась в античности - это синоним латинского «субстанция» и русского «подлежащее», «подставка». Тогда как природа (сущность) - это те специфические качества, которыми обладает данный предмет. Скажем, природа человека в строгом смысле - это то, что отличает человека от 
животного и ангельского мира. В более широком смысле «человеческая природа» - это вообще все, что свойственно человеку. Индивидуальность - это те особенности, которыми отличаются друг от друга носители одной и той же природы. Это различия людей между собой. Можно сказать, что каждый из нас лишь отчасти обладает человеческой природой - каждый на свой лад. Индивидуальность - это и есть аристотелевская «вторая природа»: сущность, явленная в конкретном многообразии.

Наконец, личность - это собственно тот субъект, который обладает всеми природно-индивидуальными свойствами. Само по себе личностное бытие качественно не выражено. Любые характеристики относятся к природе. Личность же - это тот, кто владеет этими качествами, свойствами, энергиями, кто развертывает их в реальном бытии. Природа отвечает на вопрос «что?», индивидуальность - на вопрос «как?», личность - на вопрос «кто?». Личность - субъект действий. Индивидуальность способ осуществления действий. Природа - то, что действует, источник энергий, реализованных, воплощенных действием. Личность оказывается над-качественным, над-природным бытийным стержнем, вокруг которого и группируются природные качественные признаки.

«Во Святой Троице иное есть общее, а иное особенное: общее приписывается существу, а ипостась означает особенность каждого Лица», - учит св. Василий Великий [6, с. 127]. «Первое, - говорит Св. Григорий Богослов, означает природу Божества, а последнее - личные свойства Трех» [7, с 52]. Св. Григорий Нисский разъяснял, что три Ипостаси относятся к отличному в Боге, а Бог есть имя единой и неразличимой сущности, личности [8, с. 227].

Следуя этой мысли, личность (по мнению Отцов Церкви) не является частью сущности или природы, не сводится к природному бытию, не мыслится в природных категориях.

Божественные Лица есть способ бытия Божественной природы. Это значит, что единый Бог христианства не является безличной сущностью философских спекуляций, не есть абстракция, лишенная живого личного отношения к человеку. Он имеет конкретное Личное (Ипостасное) существование, Его природа существует лично, она живое личное бытие.

Ипостасью Богочеловека Иисуса Христа в православии признается Ипостась Сына Божия, Нетварного Божественного Логоса. Ипостась Иисуса Христа именуется единой и сложной.

В Богочеловеке Иисусе Христе нет двух лиц или ипостасей. В Нем единое Лицо - Лицо Сына Божия. Лицо Сына Божия объединяет в Себе две природы - Божественную и человеческую. Прежде воплощения Ипостась Сына Божьего именуется простой, поскольку Она не пребывала в двух природах, была единоприродной Божественной Ипостасью - Логосом, Словом, Духом Божьим: «В начале было Слово, и Слово было у Бога, и Слово было Бог» (Ин. 1:1). После Воплощения Ипостась Сына Божьего названа сложной, поскольку Она усвоила, соединила в Себе две природы - Божественную и Человеческую: «И Слово стало плотию, и обитало с нами» (Ин. 1:14).

Лик Христа тем и отличается от лица, что заключает в себе равно Две Ипостаси, Две Сущности, Две Личности: Смертного сына Человеческого и Бессмертного Предвечного Бога. Можно говорить и о том, что Христос (в своей Божественной Ипостаси) и есть Образ Божий, по которому сотворен человек: «И сказал Бог: сотворим человека по образу Нашему, по подобию Нашему...» (Быт. 1: 26).

Это представление о личности и бытии расшатывается в эпоху Возрождения и в Новое время, когда на первый план выходит задача удостоверения представлений. Человек говорит себе: «Я не могу полагаться на вселенский распорядок сущего: он меня не держит. Я должен сам выяснить, кто я есть». Складывается субъект-объектная парадигма («Я», «0н» «Они», «0но»). Тут и появляется «душа психологическая» под именем «сознания» и «самосознания». Сознание как термин изобрел Джон Локк. Душа по его разумению есть именно то, что у меня в голове (на уме и в сердце), мой «внутренний» мир.

Джон Локк различает опыт внешний и опыт внутренний. Внешний опыт связан непосредственно с чувственным восприятием. А внутренний опыт - с рефлексией как «восприятием деятельности нашего ума», который сопоставляет впечатления, полученные из внешнего опыта. Этот внутренний опыт и есть душа-сознание.

Человек, пишет Локк, отличается от животного тем, что в процессе зрения, осязания, обоняния, обдумывания и прочего всегда знает, что это делает он. Таким образом, единство личности, согласно Локку, представлено в самосознании, которое является неотъемлемым моментом любого индивидуального опыта. И как раз это индивидуальное самосознание Локк превращает в исток и основание личного Я или индивидуальной души, если пользоваться традиционной терминологией.

Человек, согласно парадигме Нового времени, есть личность, которая включает в себя некоторое тело и лицо, но только таким образом и до тех пор, пока она осознает это тело как часть самой себя. Это значит, что тело, согласно Локку, присутствует в составе личности лишь в качестве собственного чувственного образа. Телесная субстанция и внешность, в соответствии с этой логикой, является фактом сознания, частью нашей личности (моя внешность есть я, если я осознаю ее моей).

Если для схоластов мыслящим началом в индивиде выступала душа как нематериальная субстанция, то у Локка, согласно концепции о тождестве личности, мыслит индивидуальное «Я», тождественное нашей жизнедеятельности и опыту и способное осмыслять самое себя. В этом новом качестве чувственный опыт отличается от опыта животных, поскольку в нем появляется новое измерение под названием «сознание». Сознание, вырастая из индивидуального опыта, в свою очередь организует и направляет его. Так выглядит эмпирическое понимание личного «Я» или человеческой души, впервые заявленное в Новое время.

Эмпирически понятая душа ограничена процес- 
сом моей непрерывной жизнедеятельности. А там, где он прерывается сном, потерей сознания или другими естественными или катастрофическими событиями, «Я» сознательно устанавливает связь своих прошлых и настоящих состояний, подтверждая тем самым цельность личности. Благодаря этому «Я» остается собой в каждом из своих состояний.

Так, лицо, некогда бывшее ипостасью высшей духовной сущности, Образом Божьим в Человеке, превращается в отражение личного «Я», в своего рода карту эмоций, на которой живо отражается «деятельность ума». «Глаза - зеркало души» - типичное утверждение Нового времени, где Лицо становится отражением внутреннего опыта, опыта личности.

Если прежде личность вырастала из единства природы и индивидуума, то в Новое время именно индивидуум выступил как определяющее качество личности. «Я», тождественное себе, есть только «Я», отраженное в зеркале. Однако в силу свойственной постмодернизму «экзистенциальной относительности» уже нельзя уверенно утверждать, что отражение в зеркале есть в точности «Я». Локк писал, что когда запахи, очертания и звуки исчезают из нашего сознания, они исчезают вовсе, становясь своего рода «свободными радикалами», витающими в пространстве. Пусть мое «Я» не таково, каким я вижу его, но таково, каким я его мыслю. Все равно, личное и зримое теряют свое прежнее тождество даже в моем сознании.

Именно конфликтный характер самовосприятия движет человеком в стремлении преобразить личность посредством изменения лица. В здешнем эмпирическом бытии лицо во многом предопределяет не только наше собственное отношение к себе, но и отношение окружающих. Вспомним хотя бы выражение «потерять лицо», которое означает стать чужим для людей, общества и для себя прежнего, что ведет к неизбежной социальной, а часто и физической смерти. Иллюстрацией к этому утверждению может послужить судьба героя романа японского писателя Кобо Абэ «Чужое лицо». Получив ожог жидким кислородом, герой романа навсегда теряет свою прежнюю внешность. После этого его мир меняется навсегда. Он не может, как прежде, общаться с семьей и другом, а любимая им до этого несчастного случая музыка кажется ему теперь не бальзамом, а комком глины. «Неужели изуродованное лицо способно влиять на восприятие музыки?» - сокрушается он. Герой размышляет, не потерял ли он еще что-то вместе с лицом.
Интересно, что если прав Локк, а иначе говоря, человек есть существо тождественное себе, в котором душа-личность равна внешности, то герой Абэ обезличен в прямом смысле слова. Без лица он уже не личность. 0 н не есть он сам.

Все ухищрения героя романа: многочисленные маски и «протезы лица», увы, не способны обмануть ни ребенка, ни умственноотсталую девушку, ни даже собаку. Не вынеся и не приняв своей новой внешности, герой Кобо Абэ сходит с ума и неизбежно погибает.

Внешность, неотделимая от личности, вступает с нею в непримиримый конфликт. Так, лицо, утратившее вместе с внешностью и ипостась (свою живую суть), становится непримиримо, непоправимо «Другим», и в этом качестве его отказывается принимать наше «Я».

Следовательно, наше лицо и личность находятся в отношениях вечной двойственности и единства в системе «Я - Другой». Они не тождественны, но и не разделимы. Лицо телесное есть маска, чистая структура и отражение личности. Лицо-личность, ипостась воплощают наше абсолютное «Я», «чистый дух», придающий лицу телесному все его живые черты и выражения. В истории мысли данная амбивалентность взаимоотношений лица и личности прошла путь от природной индивидуально-личностной средневековой парадигмы через рационалистическое тождество внешности и личности к экзистенциальной относительности.

\section{Список литературы}

1. Lacan J. Le Stade du miroir comme formateur de la fonction du Je : telle qu'elle nous est révélée dans l'expérience psychanalytique. - Paris:Presses universitaires de France, 1949.

2. Бродский И. Сочинения. В 4 т. - СПб.: Пушкинский фонд, 1992.

3. Гегель Г.В.Ф. Эстетика. В 4 т. Т. 3. / под ред. М. Лифшица. М.: Искусство, 1971.

4. Хоружий С.С. Философия Л.П. Карсавина в судьбах европейской мысли о личности // Историко-философский альманах. - 2010. - Вып. 3.

5. Лосев А.Ф. Двенадцать тезисов об античной культуре / А.Ф. Лосев, А.А. Тахо-Годи и др. Античная литература: учеб. для высшей школы. - М., 1997.

6. Основы христианской православной веры / сост. прот. Владимир Глиндский. - London; Ontario - Canada: Zaria Publ., 1985.

7. Флоренский П. Столп и утверждение Истины. - М., 1914.

8. Лосский В.Н. Догматическое богословие // Богословские труды. Вып. 8. - М., 1972. 